\title{
Archives of Plastic Surgery's efforts to become indexed in Science Citation Index Extended (SCIE) over the last 3 years
}

\author{
Yong-Ha Kim
}

Editor-in-Chief, Archives of Plastic Surgery

Department of Plastic and Reconstructive Surgery, Yeungnam University College of Medicine, Daegu, Korea

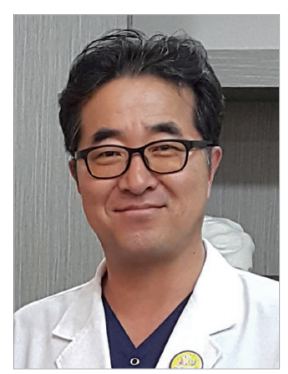

Three years ago, in 2016, Archives of Plastic Surgery (APS) prepared itself for inclusion in the Science Citation Index Extended (SCIE), but did not succeed. At that time, Thomson Reuters created a new rating system, Emerging Sources Citation Index (ESCI), which encompassed many journals that hoped to be included in SCIE. APS could not help but follow the same path.

APS, the official journal of the Korean Society of Plastic and Reconstructive Surgeons, has been applying for inclusion in SCIE since it was changed to an all-English journal in 2012. In 2016, APS was reviewed again by Thomson Reuters for inclusion in SCIE and has received notice that it will be reviewed again later this year (2019). APS was not indexed in SCIE in the last review for the following reasons: a lack of international diversity of authors, too many papers with non-citable images, and the fact that many plastic surgery titles already exist. For the last 3 years, APS has been continually striving to improve in response to the issues raised during the previous review, and further details on the process and results are presented below.

\section{INTERNATIONAL DIVERSITY OF AUTHORS}

Regarding the international diversity of authors, the recent issues of APS have regularly published articles by authors from over 20 countries, with papers written by authors from 10,25 , $20,19,22,20$, and 25 countries in 2012, 2013, 2014, 2015, 2016, 2017, and 2018, respectively. The percentage of authors from countries other than Korea has been steadily growing, with proportions of $10.14 \%, 29.94 \%$, 38.46\%, 36.09\%, 30.65\%,
$39.39 \%$, and 50.45\% in 2012, 2013, 2014, 2015, 2016, 2017, and 2018, respectively. Currently, the percentage for 2019 is $52.85 \%$. Fifty-seven editorial board members from 15 countries are active, including 29 foreign editorial board members from 14 countries other than Korea, while 306 reviewers from 41 countries are active, including 117 foreign reviewers from 40 countries other than Korea [1,2].

\section{ABOUT PAPERS WITH NON- CITABLE IMAGES}

The percentage of papers with non-citable images was high from 2012 to 2016 (15.94\%, 22 out of 138 papers in 2012; 25.74\%, 43 out of 167 papers in $2013 ; 23.07 \%$, 36 out of 156 papers in 2014; $36.09 \%, 61$ out of 169 papers in 2015; and 32.11\%, 44 out of 137 papers in 2016), but since then, it has been kept low. The percentages of papers with non-citable images in 2017 and 2018 were $9.82 \%(11 / 112)$ and $10.09 \%(11 / 109)$, respectively.

\section{JOURNALS OF PLASTIC SURGERY TITLES ALREADY EXIST}

No journal from Asia has yet been indexed in $\mathrm{SCI}(\mathrm{E})$ in the field of plastic and reconstructive surgery. This gap is noteworthy, given the need for high-quality studies from Asian countries to be well-represented in the increasingly diverse world of scientific research. Even considering the language barrier, various translation technologies have been developed in the 21st century, suggesting that it would be appropriate for APS to be in- 
dexed. The cites/document (2 years) in the SCImago Journal \& Country Rank, which is provided by Scopus, was 1.53, while its SCImago Journal Rank (SJR) was 0.717 , corresponding to second place out of 38 journals in 2018 when the scope was limited to Surgery-Asiatic Region. The estimated impact factor of APS was 1.39 (284/203), 1.47 (278/189), 1.45 (239/167), and 1.46 $(232 / 159)$ in $2015,2016,2017$, and 2018, respectively. These figures show the steady and competitive growth of APS within the plastic surgery field, with an impact factor of about 1.4 [3].

\section{OTHER EFFORTS}

APS is the official journal of PRS Korea, one of the world's largest conference in the field of plastic and reconstructive surgery, after for the American Society of Plastic Surgeons [4,5]. In Korea, the capital of plastic surgery, researchers and clinical practitioners are actively developing new ideas and techniques, and plastic surgery is widely performed. At PRS Korea 2018, 120 international invited speakers presented on various themes and 300 international plastic surgeons-not counting Korean surgeons-participated. At PRS Korea 2019, which will be held in November 2019, many prominent scholars will participate, including Alan Matarasso, the 2019 President of the American Society of Plastic Surgeons; Gregory M. Buncke, Director of the Buncke Medical Clinic; and David W. Chang, Chief of Plastic and Reconstructive Surgery at University of Chicago Medicine.

Finally, while taking steps to address the issue of publishing ethics, APS ran an editorial and review article on statistics and ethics [6,7].

Although Clarivate Analytics was spun off from Thomson Reuters, we believe that the principles underlying inclusion in SCIE remain the same. We anticipate that our ongoing efforts to be indexed in SCIE will be evaluated fairly, and that APS will become the first and only SCIE journal in the field of plastic and reconstructive surgery in Asia. Furthermore, we hope that APS will serve as the leading forum for communications in this field not only for Asian-Pacific researchers, but for researchers all over the world.

\section{NOTES}

\section{Conflict of interest}

Yong-Ha Kim has served as an editor-in-chief of the Archives of Plastic Surgery, but have no role in the decision to publish this article. Except for that, no potential conflict of interest relevant to this article was reported.

\section{ORCID}

Yong-Ha Kim https://orcid.org/0000-0002-1804-9086

\section{REFERENCES}

1. Chung KJ. The peer review system of Archives of Plastic Surgery: current status and plans for improvement. Arch Plast Surg 2019;46:187-8.

2. Song SY. A note on the current review process of Archives of Plastic Surgery. Arch Plast Surg 2019;46:289-90.

3. SCImago Journal Rank. SCImago Journal \& Country Rank [Internet]. Amsterdam: Elsevier [cited 2019 Sep 12]. Available from: https://www.scimagojr.com.

4. Choi JW. PRS Korea 2017 \& 2018: how to organize an International Plastic Surgery Congress and how to make it more attractive. Arch Plast Surg 2018;45:295-7.

5. Kim KS. Into a global future with our members to serve the people. Arch Plast Surg 2019;46:99-101.

6. Huh S. How to deal with ethical issues involving animal experiments and identifiable photographs in articles published in Archives of Plastic Surgery. Arch Plast Surg 2017;44:4756.

7. Han K, Jung I. Trends in statistical methods in articles published in Archives of Plastic Surgery between 2012 and 2017. Arch Plast Surg 2018;45:207-13.

Correspondence: Yong-Ha Kim

Department of Plastic and Reconstructive Surgery, Yeungnam University College of Medicine, 170 Hyeonchung-ro, Nam-gu, Daegu 42415, Korea

Tel: +82-53-620-3481, Fax: +82-53-626-0705, E-mail: kimyon@ynu.ac.kr

Received: September 10, $2019 \bullet$ Revised: September 10, $2019 \bullet$ Accepted: September 10, 2019 pISSN: 2234-6163 • elSSN: 2234-6171

https://doi.org/10.5999/aps.2019.01228 • Arch Plast Surg 2019;46:395-396 